\title{
Impacts of CR1 genetic variants on cerebrospinal fluid and neuroimaging biomarkers in alzheimer's disease
}

\author{
Xi-chen Zhu ${ }^{*}$ (D), Wen-zhuo Dai and Tao Ma*
}

\begin{abstract}
Background: The complement component (3b/4b) receptor 1 gene (CR1) gene has been proved to affect the susceptibility of Alzheimer's disease (AD) in different ethnic and districts groups. However, the effect of CR1 genetic variants on amyloid $\beta(A \beta)$ metabolism of $A D$ human is still unclear. Hence, the aim of this study was to investigate genetic influences of $C R 1$ gene on $A \beta$ metabolism.

Methods: All data of AD patients and normal controls (NC) were obtained from alzheimer's disease neuroimaging initiative database (ADNI) database. In order to assess the effect of each single nucleotide polymorphism (SNP) of CR1 on A $\beta$ metabolism, the PLINK software was used to conduct the quality control procedures to enroll appropriate SNPs. Moreover, the correlation between CR1 genotypes and A $\beta$ metabolism in all participants were estimated with multiple linear regression models.

Results: After quality control procedures, a total of 329 samples and 83 SNPs were enrolled in our study. Moreover, our results identified five SNPs (rs10494884, rs11118322, rs1323721, rs17259045 and rs41308433), which were linked to $A \beta$ accumulation in brain. In further analyses, rs 17259045 was found to decrease $A \beta$ accumulation among $A D$ patients. Additionally, our study revealed the genetic variants in rs 12567945 could increase CSF A $\beta_{42}$ in NC population.
\end{abstract}

Conclusions: Our study had revealed several novel SNPs in CR1 genes which might be involved in the progression of $A D$ via regulating $A \beta$ accumulation. These findings will provide a new basis for the diagnosis and treatment $A D$.

Keywords: CR1, Alzheimer's disease, Amyloid- $\beta$ (Aß) plaques, CSF A $\beta_{42}$, ADNI

\section{Highlights}

1. We found that five SNPs were linked to $A \beta$ accumulation in brain.

2. The rs17259045 decreased $A \beta$ accumulation among AD patients.

3. The rs 12567945 could increase CSF A 342 in NC population.

\footnotetext{
*Correspondence: zxc890205@163.com; tmadoc@126.com
}

Department of Neurology, the Affiliated Wuxi No. 2 People's Hospital of Nanjing Medical University, No. 68 Zhongshan Road, Wuxi, Jiangsu Province 214002, China

\section{Background}

Alzheimer's disease (AD) has been regarded as a neurodegenerative disease of the elderly, which has accounted for 47 million people worldwide with numbers predicted to rise double by 2030 and triple by 2050 [1]. As one of the most common dementia, AD has the characteristics of poor language, memory, perception, behavior and activities of daily living. Moreover, the extracellular neurotoxic amyloid- $\beta$ (A $\beta)$ plaques and intracellular neurofibrillary tangles have been regarded as the neuropathological hallmarks of $\mathrm{AD}[2]$. It has been widely confirmed that $\mathrm{AD}$ is a

(c) The Author(s). 2020 Open Access This article is licensed under a Creative Commons Attribution 4.0 International License, which permits use, sharing, adaptation, distribution and reproduction in any medium or format, as long as you give appropriate credit to the original author(s) and the source, provide a link to the Creative Commons licence, and indicate if changes were made. The images or other third party material in this article are included in the article's Creative Commons licence, unless indicated otherwise in a credit line to the material. If material is not included in the article's Creative Commons licence and your intended use is not permitted by statutory regulation or exceeds the permitted use, you will need to obtain permission directly from the copyright holder. To view a copy of this licence, visit http://creativecommons.org/licenses/by/4.0/ The Creative Commons Public Domain Dedication waiver (http://creativecommons.org/publicdomain/zero/1.0/) applies to the data made available in this article, unless otherwise stated in a credit line to the data. 
multifactorial disease, and genetic factors is proved to play a vital role in $\mathrm{AD}[3,4]$. However, in spite of the progress in understanding risk factors related to $\mathrm{AD}$ development, the underlying mechanisms involved in this disease have not been completely understood till now, and to date there is no curative treatment for $\mathrm{AD}[5,6]$.

Now many genes are proved to significantly influence $\mathrm{AD}$ risk, among which the complement component $(3 \mathrm{~b} / 4 \mathrm{~b})$ receptor 1 gene $(C R 1)$ has been proved to affect $\mathrm{AD}$ susceptibility across different ethnic and districts groups [7-12]. Currently, CR1 has been postulated to be a key factor for AD pathogenesis because of its role in regulating complement activity by acting as a receptor of complement C3b protein [13]. More importantly, in AD patients, CR1 is found to be associated with neuronal death [14] and hence has received increasing attention. Although a significant association between $\mathrm{AD}$ and single nucleotide polymorphisms (SNPs) in several novel AD loci of large case-control datasets is identified, CR1 is considered as one of the most important genetic susceptibility loci in $\mathrm{AD}$ according to the Alzgene database [15-17]. As well known, accumulation of $A \beta$ in brain is one important pathological hallmark of $\mathrm{AD}$, moreover, it is considered to induce a deleterious neurodegenerative cascade and finally cause cognitive impairments [18]. Furthermore, it has been shown that $C R 1$ takes part in $\mathrm{AD}$ pathology by regulating the amyloid protein $(A \beta)$ metabolism [19], and Johansson et al. [20] reveals that the single nucleotide polymorphisms (SNPs) in CR1 gene were associated with increased erythrocyte $C R 1$ which will finally decreased AD risk. Hence, it would be meaningful to discover the genetic variants of CR1 in $\mathrm{AD}$ development.

In this study, we enrolled the participants from the alzheimer's disease neuroimaging initiative (ADNI) database (http://www.loni.ucla.edu/ADNI), which is a multicenter project to assess the role of genetic factors in neuroimage biomarkers and cerebrospinal fluid (CSF) proteins. Next, we used PLINK software to conduct the quality control procedures to enroll appropriate SNPs in $C R 1$, and then investigated genetic influences of $C R 1$ gene on $\mathrm{A} \beta$ metabolism, in order to explore the role of $C R 1$ genetic variants in the progression of $\mathrm{AD}$.

\section{Methods}

\section{Participants}

The data in our study were obtained from the ADNI database, which contains genetic information, neuroimaging information, and CSF proteins of $\mathrm{AD}$, and normal controls (NC) (http:// www.adni-info.org). All participants of this study were included with the specific criteria according the protocol of ADNI, and then divided into two groups, including the $\mathrm{AD}$ group and $\mathrm{NC}$ group. Briefly, when participants met the National Institute of Neurological and Communicative Disorders (NINCDS) and Stroke/Alzheimer's Disease and Related Disorders Association (ADRDA) criteria for probable $\mathrm{AD}[21]$, they were diagnosed as $\mathrm{AD}$.

\section{Genotyping data}

All genetic information of SNPs of CR1 were detected using the Illumina Infinium Human610-Quad Bead Chip (Illumina, Inc., San Diego, CA) or Illumina Human Omni Express Bead Chip. And the quality control procedures were performed by using PLINK software. The SNPs would be excluded when minimum minor allele frequency (MAF) was less than 0.01 or Hardy-Weinberg $(\mathrm{H}-\mathrm{W})$ equilibrium test's value was less than 0.05 .

\section{AV45-pet}

The imaging data of PET with amyloid tracer, florbetapir (AV-45), was obtained from UC Berkeley-AV45 analysis database [22]. In order to define cortical grey matter regions of interest, these images were segmented and parcellated with Freesurfer (Version 5.3.0). After that, four regions, including the frontal, cingulate, parietal, temporal and florbetapir were involved in this study [23]. In addition, through averaging across the four cortical regions and dividing it by whole cerebellum florbetapir, the cortical standardized uptake values ratios (SUVR) were calculated [24].

\section{CSF $A \beta_{42}$ proteins}

Similarly, the data about the level of CSF $A \beta_{42}$ was also got from ADNI database. Briefly, all samples of CSF

Table 1 The details of enrolled samples from ADNI database

\begin{tabular}{llllll}
\hline Characteristics & NC & & & AD \\
\cline { 2 - 3 } & N & Mean \pm SD & & Mean \pm SD \\
\hline Age (years) & 281 & $74.51 \pm 5.56$ & & 48 & $75.51 \pm 9.23$ \\
Gender (male/female) & 281 & $136 / 145$ & & 48 & $30 / 18$ \\
Education (years) & 281 & $16.41 \pm 2.66$ & 48 & $15.73 \pm 2.62$ \\
ApoE $\varepsilon 4$ (0/1/2) & 281 & $204 / 70 / 7$ & 48 & $14 / 25 / 9$ \\
CDRSB (scores) & 207 & $6.54 \pm 0.55$ & 47 & $5.3 \pm 0.72$ \\
ADAS (scores) & 281 & $29.07 \pm 1.15$ & 48 & $22.96 \pm 2.03$ \\
MMSE (scores) & 281 & $9.06 \pm 4.23$ & & 48 & $29.8 \pm 8.44$ \\
RAVLT total (scores) & 280 & $44.83 \pm 9.6$ & & 47 & $22.32 \pm 7.84$ \\
FAQ (scores) & 281 & $0.17 \pm 0.66$ & & 48 & $12.6 \pm 7.14$ \\
\hline
\end{tabular}

$A D N /$ alzheimer's disease neuroimaging initiative, $A D$ alzheimer's disease, $A p o E$ $\varepsilon 4$ apolipoprotein $E \varepsilon 4, S D$ standard deviations, $A D A S$ alzheimer's disease assessment scale, CDRSB clinical dementia rating scale sum of boxes, $F A Q$ functional activities questionnaire, MMSE mini-mental state exam, $N C$ normal controls, RAVLT rey auditory verbal learning test 
were collected and transported to ADNI Biomarker Core laboratory at the University of Pennsylvania Medical Center. Following thawed at room temperature and gentle mixed, these samples were used for preparation of aliquots $(0.5 \mathrm{ml})$. Finally, the level of CSF $\mathrm{A} \beta_{42}$ was determined with multiplex xMAP luminex platform (Luminex Corp, Austin, TX) with immunoassay kit according to reagents [25].

\section{Statistical analyses}

All statistical analyses were determined by using the SPSS 18.0 software (SPSS Inc., Chicago, IL, USA) and PLINK (http:// pngu.mgh.harvard.edu/wpurcell/plink/). The demographic characteristics were performed with means \pm standard deviations $(\mathrm{SD})$. The t-test or chisquare test were used for the analysis of demographics and genotypic frequencies. The correlation between CR1 genotypes and $A \beta$ metabolism in all cohorts were estimated with multiple linear regression models. The false discovery rate (FDR) test was applied to control for multiple hypothesis testing [26], and a $P \leq 0.05$ was considered to be statistically significant.

\section{Results}

\section{Characteristics of included participants}

As shown in Table 1, a total of 329 individuals (48 AD and $281 \mathrm{NC}$ ) were enrolled in our study according to the quality control for genotype. Moreover, the AD group with $70.8 \%$ has higher frequency of the 84 allele within apolipoprotein $\mathrm{E}$ (ApoE) gene than the NC group with $26.3 \%$. According to the scores of different neuropsychological scales, the patients with $\mathrm{AD}$ have worse cognitive function in comparison to those NC group, respectively.

\section{Characteristics of included SNPs of CR1}

After quality control with PLINK software, a total of 83 SNPs of CR1 were enrolled in our study. Next, we used Haploview version 4.2 to explore the linkage disequilibrium (LD) patterns of these included SNPs of CR1 (Supplementary Fig. 1). The results showed these SNPs distributed from block 1 to 5 which indicated the SNPs capture most common variants in CR1. Furthermore, the characteristics (major allele, minor allele, MAF, functional consequence, position and $\mathrm{H}-\mathrm{W}$ value) of included CR1 SNPs were illustrated in supplementary Table 1. The MAF values of all included SNPs were more than 0.01 , and the $\mathrm{H}-\mathrm{W}$ values of included SNPs were more than 0.05 .

\section{The effects of CR1 genetic variants on AV-45 PET}

It is well known that the data of the AV-45 retention on the PET imaging of amyloid may represent $A \beta$ accumulation biomarkers. In the present study, our data revealed five SNPs, including rs10494884, rs11118322, rs1323721, rs17259045 and rs41308433 were significantly related to the level of tracer retention on amyloid PET imaging. Moreover, Rs10494884, RS11118322, and rs1323721 were in block 3, rs17259045 was in block 2 and RS41308433 was in block 4. As illustrated in Table 2, the variant in rs10494884 would increase $A \beta$ accumulation in temporal, frontal, and SUVR $(P=0.03392, P=$ 0.03845 and $P=0.04447)$. Similarly, rs11118322 and rs1323721 were proved to significantly increase $A \beta$ accumulation in temporal and frontal (all, $P<0.05$ ). In addition, our data revealed that the variant in rs17259045 may widely decrease the level of $A \beta$ accumulation in frontal $(P=0.007581)$, temporal $(P=$ $0.009251)$, SUVR $(P=0.01725)$, cingulated $(P=0.02512)$ and parietal $(P=0.03033)$. And rs41308433 was proved

Table 2 The association of genetic variants in CR1 gene with A $\beta$ deposition on AV-45 PET among all people

\begin{tabular}{|c|c|c|c|c|c|c|c|}
\hline SNPs & Gene regions & Position (Chromosome) & Major allele & Minor allele & Regions & $\beta$ & $P$ value \\
\hline \multirow[t]{3}{*}{ rs10494884 } & intron variant & $1: 207674531$ & G & A & temporal & 0.03364 & 0.03392 \\
\hline & & & & & frontal & 0.03543 & 0.03845 \\
\hline & & & & & SUVR & 0.02647 & 0.04447 \\
\hline \multirow[t]{2}{*}{ rs11118322 } & intron variant & 1:207674706 & $\mathrm{T}$ & C & temporal & 0.03342 & 0.03448 \\
\hline & & & & & frontal & 0.03477 & 0.04155 \\
\hline \multirow[t]{2}{*}{ rs1323721 } & intron variant & $1: 207649895$ & A & G & temporal & 0.03245 & 0.04141 \\
\hline & & & & & frontal & 0.03381 & 0.04894 \\
\hline \multirow[t]{5}{*}{ rs17259045 } & missense & 1:207609362 & A & G & frontal & -0.0773 & 0.007581 \\
\hline & & & & & temporal & -0.06968 & 0.009251 \\
\hline & & & & & SUVR & -0.05298 & 0.01725 \\
\hline & & & & & cingulate & -0.07068 & 0.02512 \\
\hline & & & & & parietal & -0.06473 & 0.03033 \\
\hline rs41308433 & intron variant & $1: 207699490$ & $A$ & C & temporal & -0.0427 & 0.04292 \\
\hline
\end{tabular}




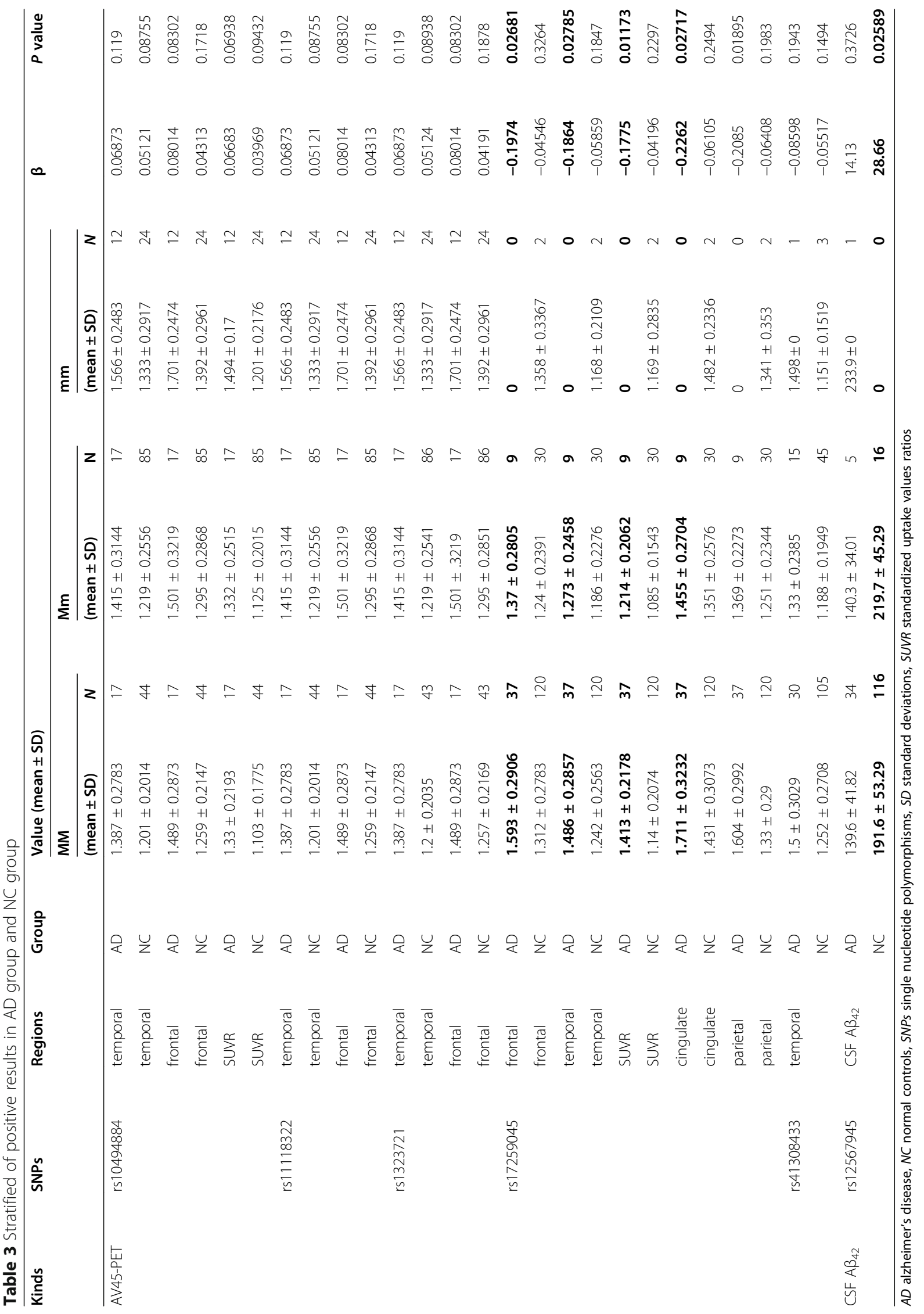




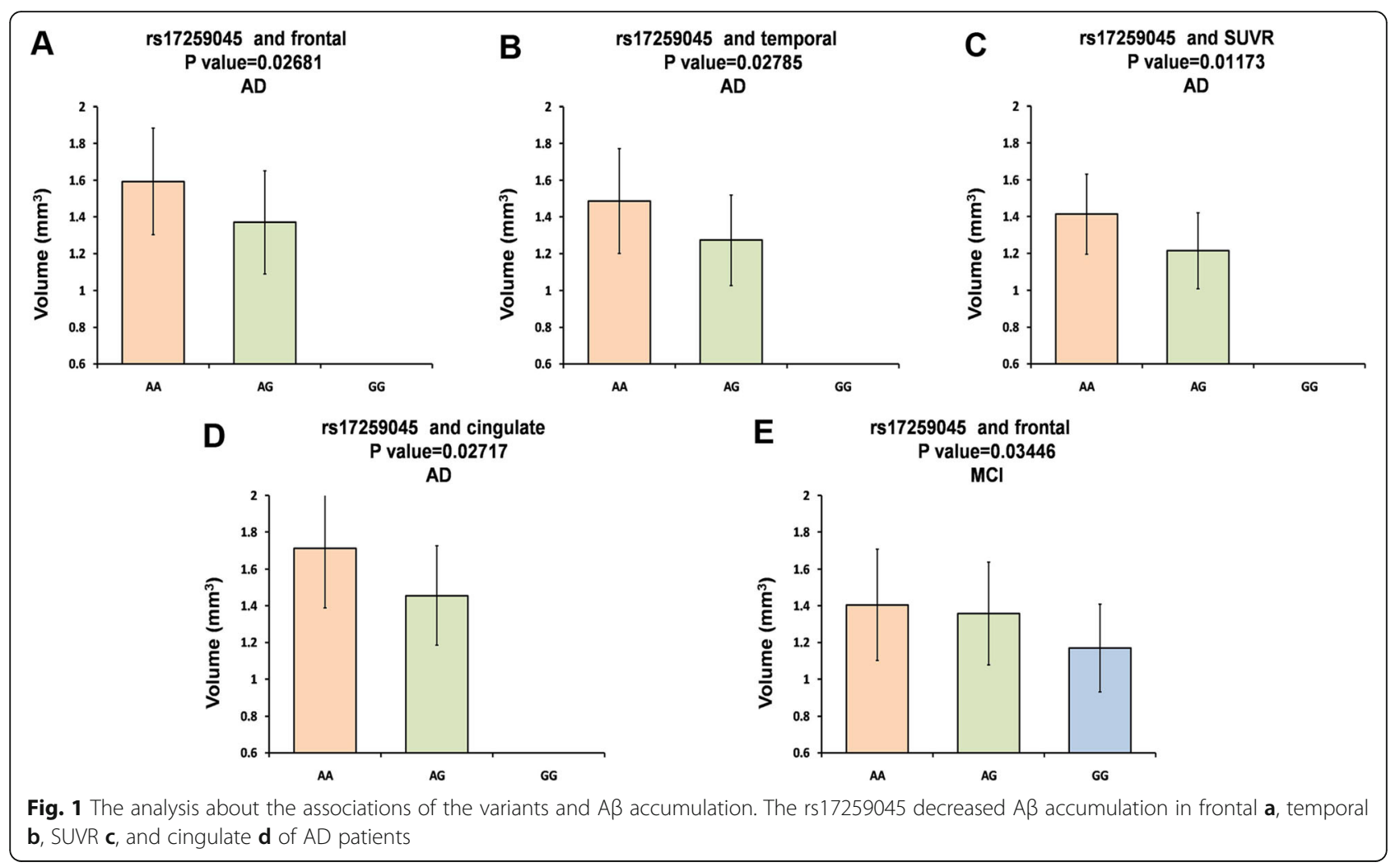

to reduce the $A \beta$ accumulation only in temporal $(P=$ 0.04292).

Then, we conducted further analyses about the associations of the variants and $A \beta$ accumulation in $A D$ and NC population. As shown in Table 3 and Fig. 1, rs17259045 may decrease $A \beta$ accumulation of $A D$ patients in frontal (AA: mean \pm SD, $1.593 \pm 0.2906, N=37$; AG: mean $\pm \mathrm{SD}, 1.37 \pm 0.2805, N=9 ; P=0.02681)$, temporal (AA: mean $\pm \mathrm{SD}, 1.486 \pm 0.2857, \mathrm{~N}=37$; AG: mean $\pm \mathrm{SD}, 1.273 \pm 0.2458, \mathrm{~N}=9 ; P=0.02785)$, SUVR (AA: mean $\pm \mathrm{SD}, 1.413 \pm 0.2178, \mathrm{~N}=37$; AG: mean $\pm \mathrm{SD}$, $1.214 \pm 0.2062, \mathrm{~N}=9 ; P=0.01173$ ), and cingulated (AA: mean $\pm \mathrm{SD}, \quad 1.711 \pm 0.3232, \mathrm{~N}=37 ; \quad$ AG: mean $\pm \mathrm{SD}$, $1.455 \pm 0.2704, \mathrm{~N}=9 ; P=0.02717)$.

\section{The effects of CR1 genetic variants on CSF $A \beta_{42}$ biomarkers}

Next, the correlations between $C R 1$ genetic variants and CSF $A \beta_{42}$ biomarkers were determined. The results indicated that rs12567945 could observably increase CSF $A \beta_{42}$ in NC population (TT: mean \pm SD, $191.6 \pm 53.29, N=116$; TC: mean \pm SD, $219.7 \pm 45.29$, $N=16 ; P=0.02589$; Table 3 and Fig. 2), which was found in block 3 .

\section{Discussion}

In our study, we explored the relation between whole $C R 1$ genetic variants and $A \beta$ metabolism biomarkers, and the results showed that five SNPs, including rs10494884, rs11118322, rs1323721, rs17259045 and rs41308433 could significantly alter $A \beta$ accumulation in brain. In further analyses, the results suggested rs17259045 might decrease $A \beta$ accumulation among $\mathrm{AD}$ patients. In addition, the genetic variants in rs12567945 would increase CSF $A \beta_{42}$ in $\mathrm{NC}$ population.

As we all known, $A \beta$ is one important pathological characteristic of $\mathrm{AD}$ [27], which may induce the activation of the classical complement pathway in $\mathrm{AD}$ brains $[28,29]$. Moreover, $C R 1$ is a necessary component of complement system, and it has been reported to have a close connection with amyloid plaque burden during aging [30, 31]. More importantly, CR1 genetic variants are found to link to intelligence decline, and may influence the eliminations of $A ß$ plaques [30]. Hence, it is urgent to investigate whether CR1 polymorphisms take part in the pathogenesis and development of LOAD. Actually, previous studies have revealed the association between CR1 SNPs and amyloid plaque $[30,32-34]$, including the CSF $A \beta$ levels [35-37]. However, the current studies only discuss the role of specific SNPs (rs6656401, rs3818361, rs670173, and rs1408077) in A $\beta$ metabolism. Briefly, rs6656401 and rs3818361, within the CR1 gene, have association with LOAD susceptibility in Caucasians [17], which are found to be in moderate $\mathrm{LD}^{\prime}\left(\mathrm{D}^{\prime}=\right.$ 

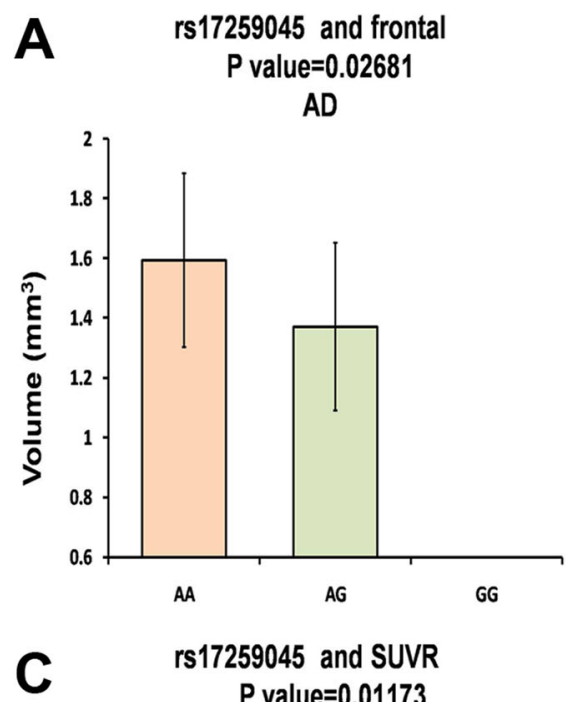

rs17259045 and SUVR

$P$ value $=0.01173$

$A D$

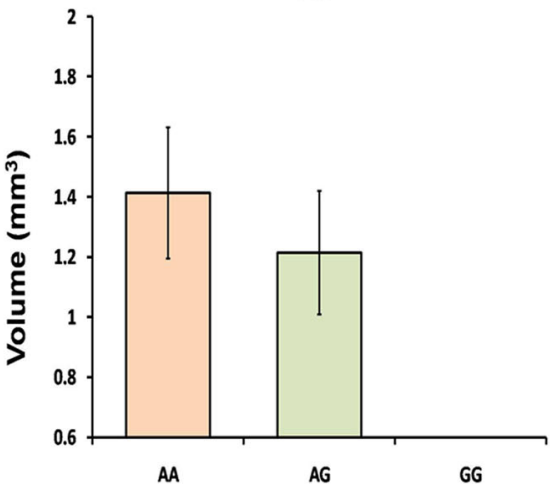

B
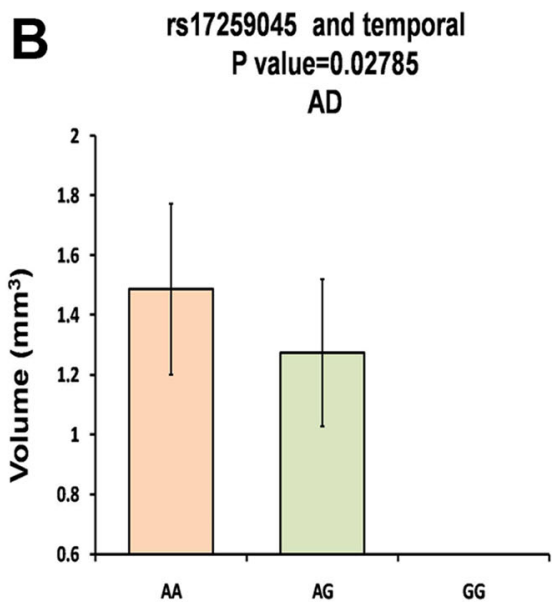

rs17259045 and cingulate $P$ value $=0.02717$

$A D$

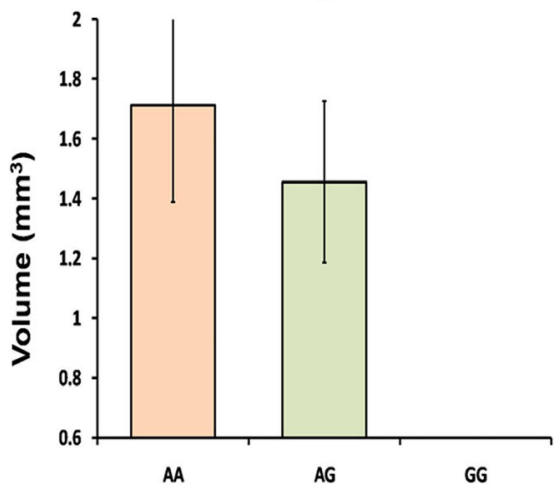

Fig. 2 Further analyses about the associations of the rs 12567945 and CSF $A \beta_{42}$ in NC population

$0.824, \mathrm{r}^{2}=0.328$ ) [38]. Specially, $\mathrm{rs} 3818361$ is found to be in block 1 [37]. In our study, the results firstly revealed that rs17259045 could reduce the level of $\mathrm{A} \beta$ accumulation among $\mathrm{AD}$ patients, respectively; moreover, rs12567945 could increase CSF $A \beta_{42}$ in $\mathrm{NC}$ population. In fact, rs17259045 was in the missense of CR1 gene, and rs12567945 located in the intron variant of $C R 1$ gene. We speculated the genetic variants in the two SNPs might modulate the level of $C R 1$, influence the activation of complement system, and finally alter the $A \beta$ metabolism in the clearance of A $\beta$ in the brain. Taken together, these results indicated that the detection of variants in $C R 1$ gene may be useful to diagnose AD timely, and it may be a useful method to treat $\mathrm{AD}$ via altering $C R 1$ level.

Our previous study had reported that several volume (entorhinal, middle temporal, posterior cingulate, precuneus, parahippocampal), volume of subcortical (amygdale and hippocampus) and CA1 (the most associated area with the AD-specific amnenstic syndrome in hippocampus) were significantly related to
AD [39]. However, our study failed to find the association between the genetic variants of CR1 (rs17259045 and rs12567945) and the above regions of interest via using ADNI data. As well know, one characteristic feature of synaptic function and density is cerebral glucose metabolic activity. Moreover, the change of glucose metabolic activity in specific brain regions could be valued via FDG PET [40]. Our study indicated that $\mathrm{AD}$ patents with genetic variants in rs17259045 might have more level of glucose metabolic activity in right angular $(P=0.03278)$. Hence, we hypothesized that genetic variants in CR1 might influence cognitive function (Fig. 3), through regulating CSF $A \beta$ level, changing $A \beta$ accumulations in brains, influencing the glucose metabolic activity, as well as altering the synaptic function and density.

\section{Conclusion}

In summary, our study found five SNPs (rs10494884, rs11118322, rs1323721, rs17259045 and rs41308433) were significantly linked to $A \beta$ accumulation in brain. In 


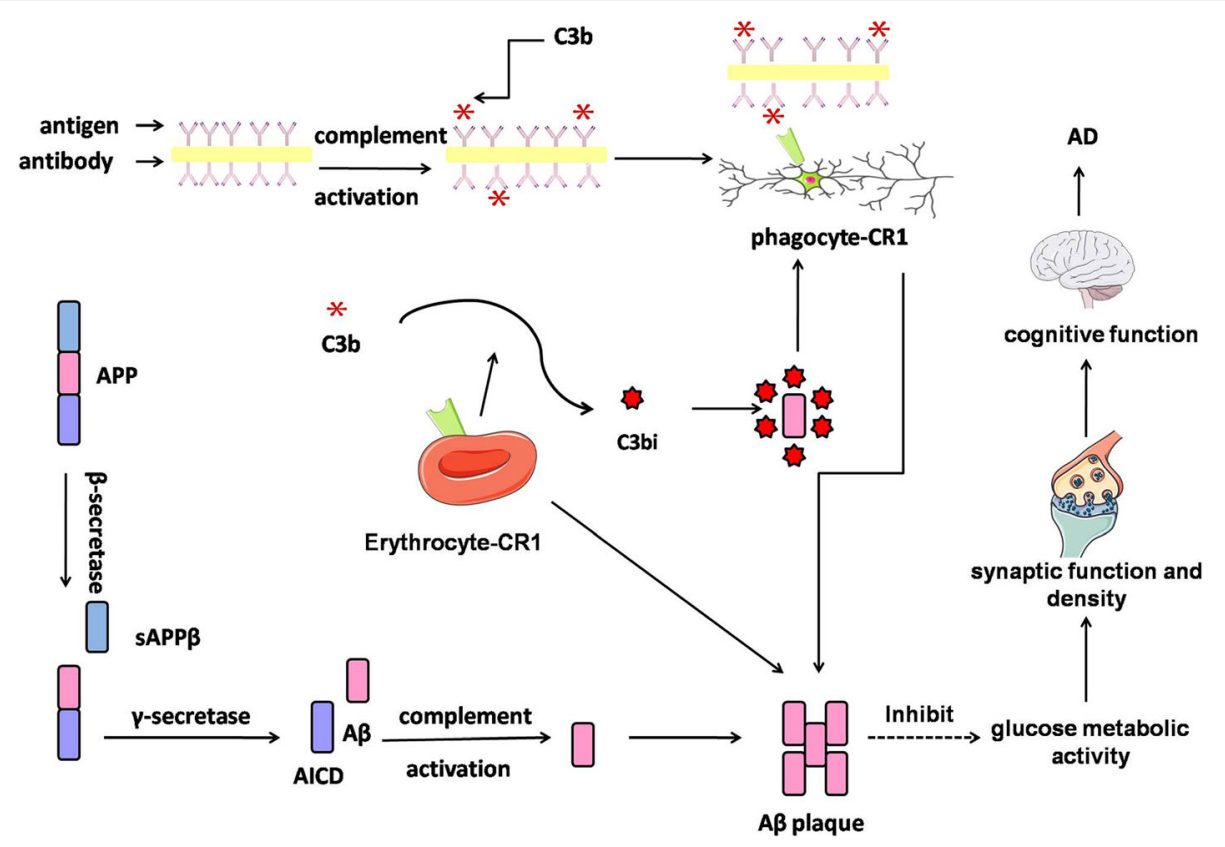

Fig. 3 The possible pathway related to $C R 1$ in $A \beta$ metabolism

further analyses of positive results, rs17259045 was found to decrease $A \beta$ accumulation among $A D$ patients. In addition, our study indicated genetic variants in rs 12567945 would increase CSF $\mathrm{A} \beta_{42}$ in NC population. Taken together, our study revealed some novel SNPs in CR1 which might be involved in $\mathrm{AD}$ development through regulating the $A \beta$ pathology. However, several limitations still exist in this study. Firstly, the numbers of included samples were relative small. Secondly, our study was explored only in Caucasians. Hence, further study with larger samples and different ethnicities is still necessary.

\section{Supplementary information}

Supplementary information accompanies this paper at https://doi.org/10. 1186/s12881-020-01114-x.

Additional file 1.

Additional file 2 .

\section{Abbreviations}

AD: Alzheimer's disease; ADNI: Alzheimer's Disease Neuroimaging Initiative; ADRDA: Alzheimer's Disease and Related Disorders Association; A 3 : amyloid$\beta_{;}$CSF: Cerebrospinal fluid; FDR: False discovery rate; MAF: Minor allele frequency; MCI: Mild cognitive impairment; MMSE: Mini-mental state examination; NC: Normal controls; NINCDS: Neurological and Communicative Disorders; SNP: Single nucleotide polymorphism; SUVR: Standardized uptake values ratios

\section{Acknowledgements}

Data used in preparation of this article were obtained from the Alzheimer's Disease Neuroimaging Initiative (ADNI) database (adni.loni.usc.edu). As such, the investigators within the ADNI contributed to the design and implementation of ADNI and/or provided data but did not participate in analysis or writing of this report. Our study was allowed to use data information by ADNI.

\section{Authors' contributions}

Conception and design of the research: Xi-chen Zhu. Acquisition of data: Xichen Zhu, Wen-zhuo Dai, Tao Ma. Analysis and interpretation of data: Wenzhuo Dai. Statistical analysis: Tao Ma. Obtaining funding: Xi-chen Zhu. Drafting the manuscript: Xi-chen Zhu. Revision of manuscript for important intellectual content: Xi-chen Zhu. All authors have read and approved the manuscript, and ensure that this is the case.

\section{Funding}

This work was supported by the National Natural Science Foundation of China (Program No. 81801054), the Natural Science Foundation of Jiangsu Province (Program No. BK20180166) and the Wuxi municipal health and Family Planning Commission Fund (Program No. Q201722).

Availability of data and materials

Not applicable. This study was only the primary research, and further study has been in progress.

Ethics approval and consent to participate

This study was approved by Ethics Committee of the Affiliated Wuxi No. 2 People's Hospital of Nanjing Medical University.

\section{Consent for publication}

Not applicable.

\section{Competing interests}

The authors declare that they have no competing interests.

Received: 20 January 2020 Accepted: 31 August 2020

Published online: 12 September 2020

\section{References}

1. Scheltens P, Blennow K, Breteler MM, de Strooper B, Frisoni GB, Salloway S,Van der Flier WM. Alzheimer's disease. Lancet (London, England). 2016; 388(10043):505-17.

2. John H, Selkoe DJ. The amyloid hypothesis of Alzheimer's disease: progress and problems on the road to therapeutics. Science (New York, NY). 2002; 297(5580):353-6. 
3. Zhu XC, Cao L, Tan MS, Jiang T, Wang HF, Lu H, Tan CC, Zhang W, Tan L, Yu JT. Association of Parkinson's disease GWAS-linked loci with Alzheimer's disease in Han Chinese. Mol Neurobiol. 2017;54(1):308-18.

4. Ertekin-Taner N. Genetics of Alzheimer's disease: a centennial review. Neurol Clin. 2007;25(3):611-67 v.

5. Zhu XC, Yu JT, Jiang T, Wang P, Cao L, Tan L. CR1 in Alzheimer's disease. Mol Neurobiol. 2015;51(2):753-65.

6. Karagiannidou M, Wittenberg R, Landeiro FIT, Park AL, Fry A, Knapp M, Gray AM, Tockhorn-Heidenreich A, Castro Sanchez AY, Ghinai I, et al. Systematic literature review of methodologies and data sources of existing economic models across the full spectrum of Alzheimer's disease and dementia from apparently healthy through disease progression to end of life care: a systematic review protocol. BMJ Open. 2018;8(6):e020638.

7. Carrasquillo MM, Belbin O, Hunter TA, Ma L, Bisceglio GD, Zou F, Crook JE, Pankratz VS, Dickson DW, Graff-Radford NR, et al. Replication of CLU, CR1, and PICALM associations with alzheimer disease. Arch Neurol. 2010;67(8): 961-4.

8. Van Cauwenberghe C, Bettens K, Engelborghs S, Vandenbulcke M, Van Dongen J, Vermeulen S, Vandenberghe R, De Deyn PP, Van Broeckhoven C, Sleegers K. Complement receptor 1 coding variant p.Ser1610Thr in Alzheimer's disease and related endophenotypes. Neurobiol Aging. 2013; 34(9):2235 e2231-2236.

9. Kisserli A, Tabary T, Cohen JHM, Duret V, Mahmoudi R. High-resolution melting PCR for complement receptor 1 length polymorphism genotyping: An innovative tool for Alzheimer's disease gene susceptibility assessment. J Visual Exp. 2017;125.

10. Lin E, Tsai SJ, Kuo PH, Liu YL, Yang AC, Kao CF. Association and interaction effects of Alzheimer's disease-associated genes and lifestyle on cognitive aging in older adults in a Taiwanese population. Oncotarget. 2017;8(15): 24077-87.

11. Almeida JFF, Dos Santos LR, Trancozo M, de Paula F. Updated meta-analysis of BIN1, CR1, MS4A6A, CLU, and ABCA7 variants in Alzheimer's disease. J Mol Neurosci. 2018;64(3):471-7.

12. Sapkota S, Dixon RA. A network of genetic effects on non-demented cognitive aging: Alzheimer's genetic risk (CLU + CR1 + PICALM) intensifies cognitive aging genetic risk (COMT + BDNF) selectively for APOEvarepsilon4 carriers. J Alzheimer's Dis. 2018;62(2):887-900.

13. Karch CM, Jeng AT, Nowotny P, Cady J, Cruchaga C, Goate A. Expression of novel Alzheimer's disease risk genes in control and Alzheimer's disease brains. PLoS One. 2012;7(11).

14. Crehan H, Hardy J, Pocock JM. Blockage of CR1 prevents activation of rodent microglia. Neurobiol Dis. 2013;54:139-49.

15. Weiner MW, Veitch DP, Aisen PS, Beckett LA, Cairns NJ, Green RC, Harvey DJ, Jack CRJ, Jagust WJ, Liu E. The Alzheimer's Disease Neuroimaging Initiative: A review of papers published since its inception. Alzheimers Dement. 2012; $9(5)$.

16. Carrasquillo MM, Belbin O, Hunter TA, Ma L, Bisceglio G, Zou F, Crook JE, Pankratz VS, Dickson DW, Graffradford NR. Replication of CLU, CR1, and PICA LM associations with Alzheimer disease. JAMA Neurol. 2010;67(8):961-4.

17. Lambert JC, Heath S, Even G, Campion D, Sleegers K, Hiltunen M, Combarros O, Zelenika D, Bullido MJ, Tavernier B. Genome-wide association study identifies variants at CLU and CR1 associated with Alzheimer'ss disease. Nat Genet. 2009:41(10):1094-9.

18. Gulisano W, Maugeri D, Baltrons MA, Fa M, Amato A, Palmeri A, Luciano D'Adamio, Grassi C, Devanand DP, Honig LS et al: Role of amyloid-beta and tau proteins in Alzheimer's disease: confuting the amyloid Cascade. J Alzheimer's Dis 2018.

19. Rogers J, Li R, Mastroeni D, Grover A, Leonard B, Ahern G, Cao P, Kolody H, Vedders $L$, Kolb WP, et al. Peripheral clearance of amyloid beta peptide by complement C3-dependent adherence to erythrocytes. Neurobiol Aging 2006;27(12):1733-9.

20. Johansson JU, Brubaker WD, Javitz H, Bergen AW, Nishita D, Trigunaite A, Crane A, Ceballos J, Mastroeni D, Tenner AJ et al: Peripheral complement interactions with amyloid beta peptide in Alzheimer's disease: polymorphisms, structure, and function of complement receptor 1 . Alzheimer's Dementia : the journal of the Alzheimer's Association 2018.

21. McKhann GM, Knopman DS, Chertkow H, Hyman BT, Jack CR Jr, Kawas CH, Klunk WE, Koroshetz WJ, Manly JJ, Mayeux R, et al. The diagnosis of dementia due to Alzheimer's disease: recommendations from the National Institute on Aging-Alzheimer's Association workgroups on diagnostic guidelines for Alzheimer's disease. Alzheimer's Dementia. 2011;7(3):263-9.
22. Landau SM, Mintun MA, Joshi AD, Koeppe RA, Petersen RC, Aisen PS, Weiner MW, Jagust WJ. Amyloid deposition, hypometabolism, and longitudinal cognitive decline. Ann Neurol. 2012;72(4):578-86.

23. Mormino EC, Betensky RA, Hedden T, Schultz AP, Amariglio RE, Rentz DM, Johnson KA, Sperling RA. Synergistic effect of beta-amyloid and neurodegeneration on cognitive decline in clinically normal individuals. JAMA Neurol. 2014;71(11):1379-85.

24. Landau SM, Breault C, Joshi AD, Pontecorvo M, Mathis CA, Jagust WJ, Mintun MA. Amyloid-beta imaging with Pittsburgh compound $B$ and florbetapir: comparing radiotracers and quantification methods. J Nuclear Med. 2013:54(1):70-7.

25. Shaw LM, Vanderstichele H, Knapik-Czajka M, Figurski M, Coart E, Blennow K, Soares $\mathrm{H}$, Simon AJ, Lewczuk P, Dean RA, et al. Qualification of the analytical and clinical performance of CSF biomarker analyses in ADNI. Acta Neuropathol. 2011:121(5):597-609.

26. Hochberg Y, Benjamini Y. More powerful procedures for multiple significance testing. Stat Med. 1990;9(7):811-8.

27. Patel TK, Holtzman DM. Dual therapy for Abeta amyloidosis in AD: a successful one-two combo. J Exp Med. 2018;215(5):1267-8.

28. Lashkari K, Teague G, Chen H, Lin YQ, Kumar S, McLaughlin MM, Lopez FJ. A monoclonal antibody targeting amyloid beta (Abeta) restores complement factor I bioactivity: potential implications in age-related macular degeneration and Alzheimer's disease. PLoS One. 2018;13(5):e0195751.

29. Matsuo K, Shindo A, Niwa A, Tabei Kl, Akatsu H, Hashizume Y, Akiyama H, Ayaki T, Maki T, Sawamoto $\mathrm{N}$, et al. Complement activation in capillary cerebral amyloid Angiopathy. Dement Geriatr Cogn Disord. 2017:44(5-6):343-53.

30. Chibnik LB, Shulman JM, Leurgans SE, Schneider JA, Wilson RS, Tran D, Aubin C, Buchman AS, Heward CB, Myers AJ, et al. CR1 is associated with amyloid plaque burden and age-related cognitive decline. Ann Neurol. 2011;69(3):560-9.

31. Gandy S, Haroutunian V, DeKosky ST, Sano M, Schadt EE. CR1 and the "vanishing amyloid" hypothesis of Alzheimer's disease. Biol Psychiatry. 2013; 73(5):393-5.

32. Karch CM, Jeng AT, Nowotny P, Cady J, Cruchaga C, Goate AM. Expression of novel Alzheimer's disease risk genes in control and Alzheimer's disease brains. PLoS One. 2012;7(11):e50976.

33. Beecham GW, Hamilton K, Naj AC, Martin ER, Huentelman M, Myers AJ, Corneveaux JJ, Hardy J, Vonsattel JP, Younkin SG, et al. Genome-wide association meta-analysis of neuropathologic features of Alzheimer's disease and related dementias. PLoS Genet. 2014;10(9):e1004606.

34. Thambisetty M, An Y, Nalls M, Sojkova J, Swaminathan S, Zhou Y, Singleton $A B$, Wong DF, Ferrucci L, Saykin AJ, et al. Effect of complement CR1 on brain amyloid burden during aging and its modification by APOE genotype. Biol Psychiatry. 2013;73(5):422-8.

35. Schjeide BM, Schnack C, Lambert JC, Lill CM, Kirchheiner J, Tumani H, Otto $M$, Tanzi RE, Lehrach $H$, Amouyel P, et al. The role of clusterin, complement receptor 1 , and phosphatidylinositol binding clathrin assembly protein in Alzheimer disease risk and cerebrospinal fluid biomarker levels. Arch Gen Psychiatry. 2011;68(2):207-13.

36. Schott JM. Using CSF biomarkers to replicate genetic associations in Alzheimer's disease. Neurobiol Aging. 2012;33(7):1486 e1489-1415.

37. Zhu X, Wang H, Jiang T, Lu H, Tan M, Tan C, Tan L, Tan L, Yu J, Initiative ADN. Effect of CR1 genetic variants on cerebrospinal fluid and neuroimaging biomarkers in healthy, mild cognitive impairment and Alzheimer's disease cohorts. Mol Neurobiol. 2017;54(1):551-62.

38. Zhang Q, Yu J, Zhu Q, Zhang W, Wu Z, Miao D, Tan L. Complement receptor 1 polymorphisms and risk of late-onset Alzheimer's disease. Brain Res. 2010;1348:216-21.

39. Zhu XC, Wang HF, Jiang T, Lu H, Tan MS, Tan CC, Tan L, Yu JT. Effect of CR1 genetic variants on cerebrospinal fluid and neuroimaging biomarkers in healthy, mild cognitive impairment and Alzheimer's disease cohorts. Mol Neurobiol. 2017;54(1):551-62.

40. Morbelli S, Bauckneht M, Arnaldi D, Picco A, Pardini M, Brugnolo A, Buschiazzo A, Pagani M, Girtler N, Nieri A, et al. 18F-FDG PET diagnostic and prognostic patterns do not overlap in Alzheimer's disease (AD) patients at the mild cognitive impairment (MCl) stage. Eur J Nucl Med Mol Imaging. 2017:44(12):2073-83

\section{Publisher's Note}

Springer Nature remains neutral with regard to jurisdictional claims in published maps and institutional affiliations. 